Huang, S., Malara, A., Zuo, W., Sohn, M. “A Bayesian Network Model for the Optimization of a Chiller Plant's Condenser Water Set Point," Journal of Building Performance Simulation, 11 (1), pp 36-47, 2018.

\title{
A Bayesian Network Model for the Optimization of a Chiller Plant's Condenser Water Set Point
}

\author{
Sen Huang ${ }^{\mathrm{a},+}$, Ana Carolina Laurini Malara ${ }^{\mathrm{b}}$, Wangda Zuo ${ }^{\mathrm{a}, *}$, Michael D. Sohn ${ }^{\mathrm{c}}$ \\ ${ }^{a}$ Department of Civil, Architectural and Environmental Engineering, University of Miami,
} 1251 Memorial Drive, Coral Gables, FL 33146, U.S.A.

${ }^{b}$ Institute of Mathematics and Computer Science, University of São Paulo,

São Paulo, 13566-590, Brazil

${ }^{c}$ Energy Analysis and Environmental Impacts Division, Lawrence Berkeley National Laboratory, 1 Cyclotron Road, Berkeley, CA 94720, U.S.A.

${ }^{+}$Current Address: Electricity Infrastructure and Buildings Division, Pacific Northwest National Laboratory, 902 Battelle Boulevard, WA 99354, U.S.A.

* Corresponding author:w.zuo@miami.edu 


\title{
A Bayesian Network Model for the Optimization of a Chiller Plant's Condenser Water Set Point
}

\author{
Abstract: To implement the condenser water set point optimization, one can employ a \\ regression model. However, existing regression-based methods have difficulties to handle \\ non-linear chiller plant behavior. To address this problem, we develop a Bayesian Network \\ model and compare it to both a linear and a polynomial regression models via a case study. \\ The results show that the Bayesian Network model can predict the optimal condenser water \\ set points with a lower root mean square deviation (RMSD) for both a mild month and a \\ summer month than the linear and the polynomial models. The energy saving ratios by the \\ Bayesian Network model are $25.92 \%$ and $1.39 \%$ for the mild month and the summer \\ month, respectively. As a comparison, the energy saving ratios by the linear and the \\ polynomial models are less than $19.00 \%$ for the mild month and even lead to more energy \\ consumption in the summer month (up to $3.73 \%$ ).
}

Keywords: Bayesian Network; Condenser Water Set Point; Regression-based Optimization 


\section{Introduction}

In the United States, a significant portion of the energy consumption by the commercial building cooling is attributed to chiller plants (Westphalen and Koszalinski 2001). Aiming at enhancing the operational efficiency of chiller plants, many researchers have devoted significant efforts to optimize the control of the general functions of an overall plant. As a result, many successful methods have been developed (Braun and Diderrich 1990; Chang et al. 2015; Chang 2004; Yu and Chan 2007; Lee and Lin 2009; Chua et al. 2013; Li, Huang, and Sun 2014; Lu et al. 2004; Ma et al. 2008; Lee and Cheng 2012; Huang and Zuo 2014; Sun and Reddy 2005; Yu and Chan 2008; Zhang et al. 2011; Sun, Wang, and Xiao 2013; Huang, Zuo, and Sohn 2015, 2016a; Malara et al. 2015). For example, Braun and Diderrich (1990) developed a method to optimize the speeds of cooling tower fans. Chang (2004) proposed a method to optimize the sequencing control for chillers. Sun, Wang, and Xiao (2013) applied an online computed chiller maximum cooling capacity method and an advanced data fusion technique in chiller sequencing control systems.

Among these methods, predicting the optimal condenser water set point has gained a lot of attention because it can provide substantial energy savings (Lu et al. 2004; Ma et al. 2008; Lee and Cheng 2012; Huang and Zuo 2014; Sun and Reddy 2005; Yu and Chan 2008; Zhang et al. 2011). The condenser water set point is the set point temperature of the condenser water leaving the cooling towers. A plant operator can adjust the condenser water set point to control the temperature of the condenser water entering the chillers. The value of the temperature of the condenser water entering the chillers has a direct impact on the energy performance of both the chillers and the cooling towers. For example, a higher temperature of the condenser water entering the chillers can reduce the cooling tower energy consumption since the cooling tower 
fans do not need to run too hard to cool the condenser water. Conversely, a warmer temperature of the condenser water entering the chillers will cause chillers to use more energy to meet cooling loads (ASHRAE 2011). It is possible to find an optimal condenser water set point which minimizes the total energy consumption of chillers and cooling towers. However, finding the optimal condenser water set point is challenging since chiller plant systems are typically nonlinear systems. For example, the energy performance curves of the chillers and cooling towers are usually non-linear.

Some researchers (Lu et al. 2004; Ma et al. 2008; Lee and Cheng 2012; Huang and Zuo 2014; Huang, Zuo, and Sohn 2016a, 2016b) have developed methods that searched for the optimal condenser water set point using system models coupled with optimization algorithms. These methods are typically referred to as model-based optimization methods. Lu et al. (2004) proposed a model-based optimization method to find the optimal condenser water set points of a chiller plant. They found that this method could save around $10 \%$ energy consumption by the condenser water loop during high load periods compared to the baseline in which the cooling tower fans and the condenser water pump are always running at full speeds. Ma et al. (2008) developed a model-based optimization method that can achieve $0.90 \%$ annual consumption saving by the chillers and cooling towers compared to the baseline in which the approach temperature (the difference between the temperature of the condenser water leaving the cooling towers and the wet bulb temperature) is kept constant. Lee and Cheng (2012) established a model-based optimization method to search the optimal condenser water set points and the set points for the chilled water of a chiller plant. The results suggest that they could achieves up to $11.1 \%$ daily energy saving for the chiller plant compared to the baseline in which the condenser water set point and the set point for the chilled water are both constant. Huang and Zuo (2014) 
demonstrated a similar approach that can achieve around 9\% annual energy saving for the chillers and the cooling towers compared to the baseline in which the condenser water set point is constant. Although the above model-based optimization methods have shown promising results, they have one limitation: they need to perform the simulation runs and the optimization of the set-point temperature in real time. This may cause challenges for legacy building systems, which have limited computational resource (Ma et al. 2009).

To address the limitation of the model-based optimization methods, researchers have proposed various regression-based methods to optimize the condenser water set point (Sun and Reddy 2005; Yu and Chan 2008; Zhang et al. 2011). For example, Sun and Reddy (2005) used a linear regression model to predict the optimal condenser water set points according to the wet bulb temperature and the cooling load:

$$
T_{c w, \text { set }, \text { opt }}=a_{1}+a_{2} T_{w b}+a_{3} \frac{\dot{Q}}{\dot{Q}_{\text {nom }}},
$$

where $T_{c w, s e t, o p t}$ is the optimal condenser water set point, $T_{w b}$ is the wet bulb temperature, $\dot{Q}$ is the cooling load while $\dot{Q}_{n o m}$ is the nominal cooling load. The $a_{1}, a_{2}$, and $a_{3}$ are regression coefficients.

Yu and Chan (2008) developed a polynomial regression model to predict the optimal condenser water set points based on the wet bulb temperature and the cooling load in order to consider the nonlinearity in the actual system:

$$
T_{c w, s e t, o p t}=b_{1}+T_{w b}+b_{2} \frac{\dot{Q}}{\dot{Q}_{\text {nom }}}+b_{3}\left(\frac{\dot{Q}}{\dot{Q}_{\text {nom }}}\right)^{2},
$$

where the $b_{1}, b_{2}$, and $b_{3}$ are regression coefficients.

Compared with the model-based optimization methods, the regression-based methods can predict an optimal condenser water set point in real time since they do not require solving 
complicated equations resulting from system models and do not need to run complicated optimization algorithms. In addition, they are simple and easy to implement in real chiller plants. These advantages make the regression-based methods quite attractive for real-world applications.

Although fast and simple, the existing regression methods do not always achieve the optimal energy savings due to the low accuracy in predicting the optimal condenser water set points. Ma et al. (2008) compared the performance of a model-based optimization method with that of the regression-based method proposed by Sun and Reddy (2005). They found that the annual energy saving for the chillers and the cooling towers by the model-based optimization method was $183,495 \mathrm{kWh}$ while that by the regression model method was only $130,236 \mathrm{kWh}$. Thus, the model-based optimization method can achieve $41 \%$ more energy savings than the regression-based method.

It is likely that suboptimal condenser water set points generated by Sun and Reddy (2005)'s method are due to difficulties in representing the nonlinear relationships in the chiller and the cooling tower operation with linear or polynomial regression models. With that in mind, we develop a Bayesian Network model, which is a data-driven probabilistic graphical model and it can handle the complicated nonlinear relationships between the variables (Imoto et al. 2005). Bayesian Network models have already been employed in the building industry for other applications. For instance, Jensen, Toftum, and Friis-Hansen (2009) employed a Bayesian Network model to estimate the effects of the thermal indoor environment on the mental performance of office workers. Toftum, Andersen, and Jensen (2009) used a Bayesian Network model to calculate how the indoor temperature set point affected the performance of occupancies 
and building energy consumption. O'Neill (2014) utilized a Bayesian Network model to establish the system model for building systems.

Recently, we started to explore the possibility of applying a Bayesian Network model in the optimal selection of the condenser water set point (Malara et al. 2015). Based on that preliminary work, this paper makes three new contributions to the literature: first, we completed the research by developing a reproducible procedure regarding how to implement the proposed Bayesian Network model in real controllers; second, we compared the performance of the Bayesian Network model with that of a linear regression model and a polynomial regression model, both are recommended by the previous studies. The comparison shows that the proposed Bayesian Network can significantly increase the accuracy in predicting the optimal condenser water set points; third, we find that condenser water set point optimizations based on the linear regression model and the polynomial regression model may cause more energy consumption for chillers and cooling towers, which hasn't be reported in the literature yet.

In this paper, we first describe the Bayesian Network model. We then perform a case study to evaluate the performance of the proposed Bayesian Network model for the optimization of the condenser water set point. In the case study, we trained the Bayesian Network model, a linear model, and a polynomial model with the same training dataset. We used the trained three models to predict the optimal condenser water set points for two testing months and compared their performance in terms of the accuracy in the condenser water set point prediction and resulting energy savings. 


\section{Bayesian Network Model}

\subsection{Bayesian Network Theory}

As shown in Figure 1, the structure of a Bayesian Network model includes two components: nodes and arcs. The nodes (e.g. $X_{a}$ to $X_{f}$ in Figure 1) represent variables that comprise the studied system. The arcs indicate the dependencies between the nodes. In the Bayesian Network model, dependencies are typically expressed as probabilistic and/or conditional probabilistic expressions. A node that affects other nodes is called a parent node (e.g. $X_{a}$ and $\left.X_{f}\right)$ and a node that is impacted by other nodes is called a child node (e.g. $X_{b}$ and $X_{d}$ ). Of course, a node can be both a parent node and a child node (e.g. $X_{b}$ and $X_{c}$ ).

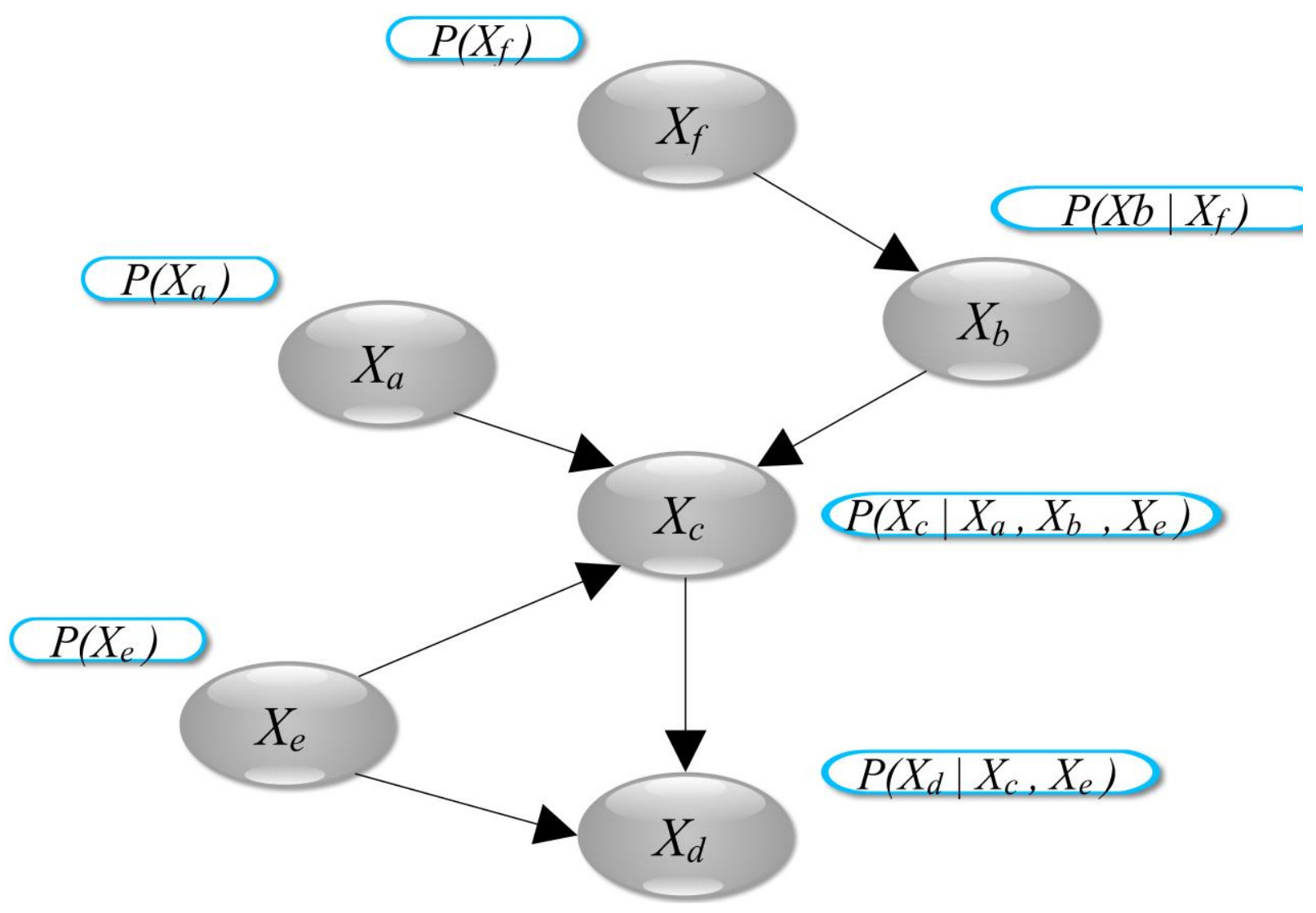

Figure 1. The structure of a typical Bayesian Network model 
The conditional probabilistic relationships of the arcs are typically defined by the relationship between parent and child nodes. For example, for one child node $X_{0}$, its conditional probability given the state of its parent nodes set $X_{P}$ is:

$$
P\left(X_{0} / X_{P}\right)=P\left(X_{0}, X_{P}\right) / P\left(X_{P}\right)
$$

where $X_{P}=\left\{X_{1}, \ldots, X_{n}\right\}$ is the set of parent nodes for $X_{0} . P\left(X_{0}, X_{P}\right)$ is the joint probability of $X_{0}$ and $X_{P}$, and $P\left(X_{P}\right)$ is the probability of each state of $X_{P}$.

\subsection{Developing Bayesian Network Model}

A typical procedure of developing a Bayesian Network model for a control optimization scheme consists of six steps. 


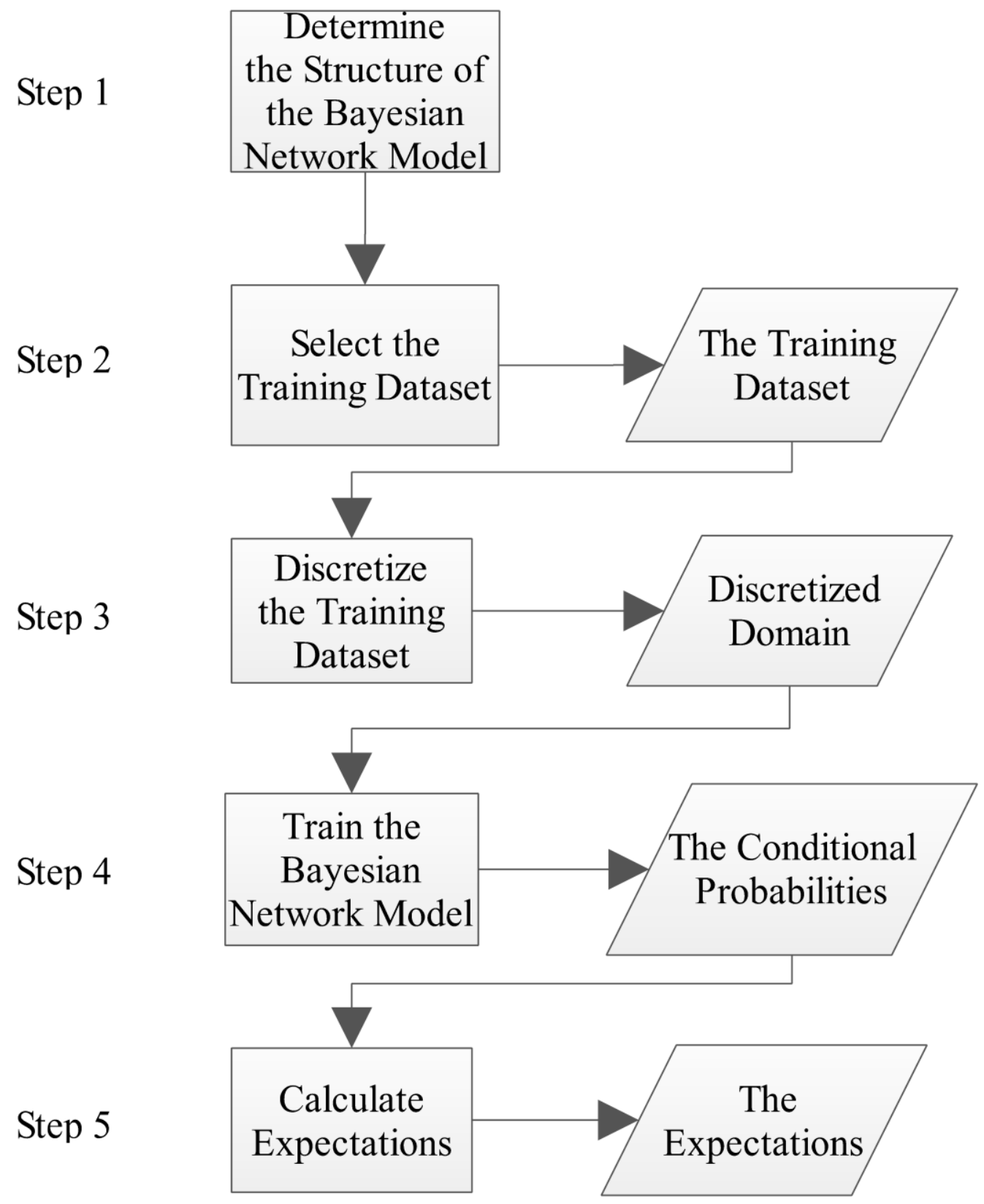

Figure 2. The flow chart of developing a Bayesian Network model for the control optimization

Step 1: Determine the Structure of the Bayesian Network Model. The structure of the Bayesian Network model consists of the nodes and the arcs shown in Figure 1. The first step is to decide on the nodes that relate inputs and outputs of the Bayesian Network model. This step also 
requires the development of the conditional probabilistic relationships of the arcs. We will discuss how we do so in the forthcoming case study.

Step 2: Select or Generate a Training Dataset. Based on the identified relevant variables in the Bayesian Network model, we select or generate a training dataset. The training dataset is used to help express the relationships between the child nodes and the parent nodes. When necessary or suitable, the training dataset can be selected using simulations.

Step 3: Discretize the Training Dataset. In this study, we used a discrete Bayesian network model. The detailed information about the discrete Bayesian network model can be found in (Cobb, Rum, and Salmerón 2007). In the control domain, variables in the training dataset often have continuous values. To deal with continuous variables using the discrete Bayesian Network model, we discretize these continuous variables and turn the training dataset into the discretized domain (Friedman and Goldszmidt 1996). By doing this, the Bayesian Network can capture the rough characteristics of the distribution of the continuous variables. To perform a discretization, we can parse the probabilistic range of the variables uniformly from the interval lengths much like one does for Latin Hypercube sampling (Helton and Davis 2003).

Step 4: Train the Bayesian Network Model. We train the Bayesian Network model by determining all the probabilities for the nodes, and the conditional probabilities for the arcs. One method for doing so, which we used for the case study that follows, is to count the frequencies of each possible value for each of the nodes. These frequencies are used to calculate the conditional probabilities of the arcs using Equation (3). 
Step 5: Calculate Expectations. In step 4, we obtained the conditional probabilities for arcs. We then need to calculate the expectations of child nodes for given states of the parent nodes. The expectation for the child node $X_{0}$ is calculated by:

$$
E\left(X_{0}=x_{i} \mid X_{P}=x_{p}\right)=\sum_{i=1}^{m} x_{i} P\left(X_{0}=x_{i} \mid X_{P}=x_{p}\right),
$$

where $x_{i}$ is one possible value of $X_{0}, m$ is the total number of the possible values of $X_{0}$, and $x_{p}$ is one state for $X_{P}$.

Step 6: Generate a Look-up Table. To facilitate the implementation of the Bayesian Network model, we convert the expectations for child nodes and the corresponding states of parent nodes into a multiple-dimensional look-up table. A look-up table is used to represent the conditional probabilistic expressions or function references of the control logic by using its relative column position in the association list. A look-up table is very easy to view and update and its use includes different computational tasks (Kim, Kim, and An 2011; Coffey 2011; Wang and Boyd 2010). The generated look-up table can be directly implemented through the programmable logic controllers (Al-Ali, Negm, and Kassas 2000) or incorporated into building automation systems (Coffey 2011).

\section{Case Study}

\subsection{Case Description}

As a case study, we consider a real chiller plant in operation. As shown in Figure 3, the studied chiller plant consists of three identical chillers, three identical chilled water pumps, three identical condenser water pumps, and three identical cooling towers. The chillers have a nominal capacity of $2,799 \mathrm{~kW}$ (the model is Trane_CVHF_2799kW). The temperature of the chilled 
water leaving the chiller is set at $6.7^{\circ} \mathrm{C}$. For the cooling tower, the nominal fan power is $37 \mathrm{~kW}$, the nominal wet bulb temperature is $25.0^{\circ} \mathrm{C}$, and the nominal approach temperature (the difference between the temperature of the condenser water leaving the cooling tower and the wet bulb temperature) is $1.1^{\circ} \mathrm{C}$. In the condenser water loop, there is a bypass valve, which is modulated to ensure that the temperature of the condenser water entering the chillers is not less than $15.0^{\circ} \mathrm{C}$. Each cooling tower consists of a variable speed fan controlled by one condenser water set point.

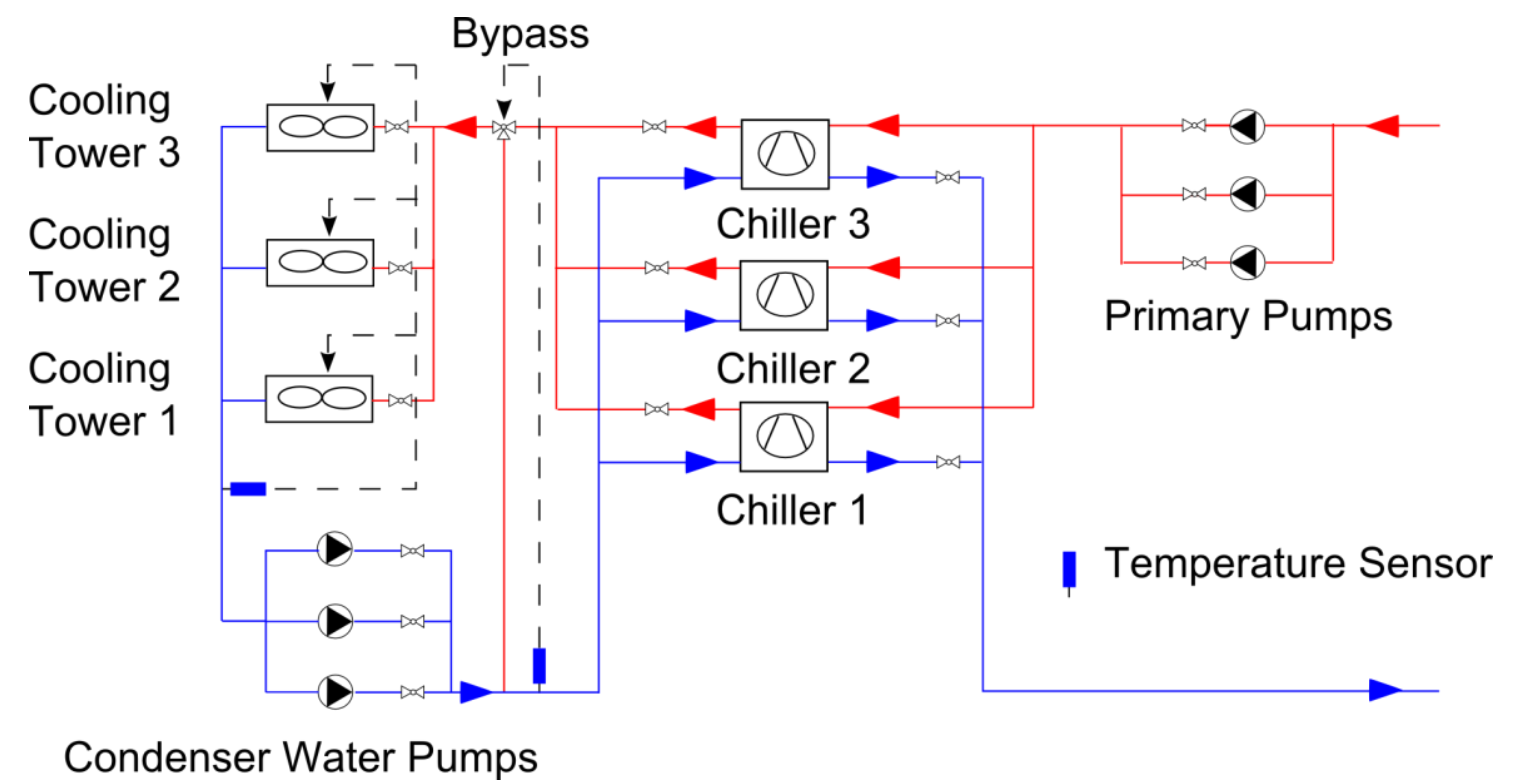

Figure 3. The schematic of the studied chiller plant

\subsection{Bayesian Network Model for Condenser Water Set Point Optimization}

For the studied chiller plant, the primary chilled water pumps and condenser water pumps are constant speed pumps. For each cooling tower, there is a variable speed fan controlled by one condenser water set point. We assume that all the cooling towers are controlled by the same condenser water set point and there is no other independent variable in the optimization. Since the change of the condenser water set point doesn't affect the operation of pumps for the studied plant, 
if we assume the thermal and hydraulic dynamics are negligible, the total power of the chillers and cooling towers, $P_{\text {sum }}$, can be described as

$$
P_{\text {sum }}=f_{1}\left(T_{c w, s e t}, \dot{Q}, T_{w b}\right)
$$

where $T_{c w \text {,set }}$ is the condenser water set point.

Based on Equation (5), we defined the following optimization problem,

$$
J=\min \left(P_{\text {sum }}\right)=\min \left(f_{1}\left(T_{c w, s e t}, \dot{Q}, T_{w b}\right)\right) .
$$

The input variables are the cooling load and the wet bulb temperature. The cooling load and the wet bulb temperature can be obtained through real-time measurement (the cooling load is calculated according to the measured flow rate and temperature difference of the chilled water). The optimized variable is the condenser water set point while the objective function is the total power of the chillers and cooling towers. Thus, the optimal condenser water set point, $T_{c w, s e t, o p t}$, that minimizes the total power of the chillers and cooling towers is a function of the cooling load and the wet bulb temperature:

$$
T_{c w, s e t, o p t}=f_{2}\left(\dot{Q}, T_{w b}\right)
$$

Based on equation (7), we build a Bayesian Network model structure shown in Figure 4. In this Bayesian Network model, the parent nodes are the cooling load and the wet bulb temperature while the child node is the optimal condenser water set point and is limited in a certain range to avoid obviously negative impacts on the chiller operation (overcooling or overheating). In this case, the range is set to be $[15.1,26.1]\left({ }^{\circ} \mathrm{C}\right)$. 


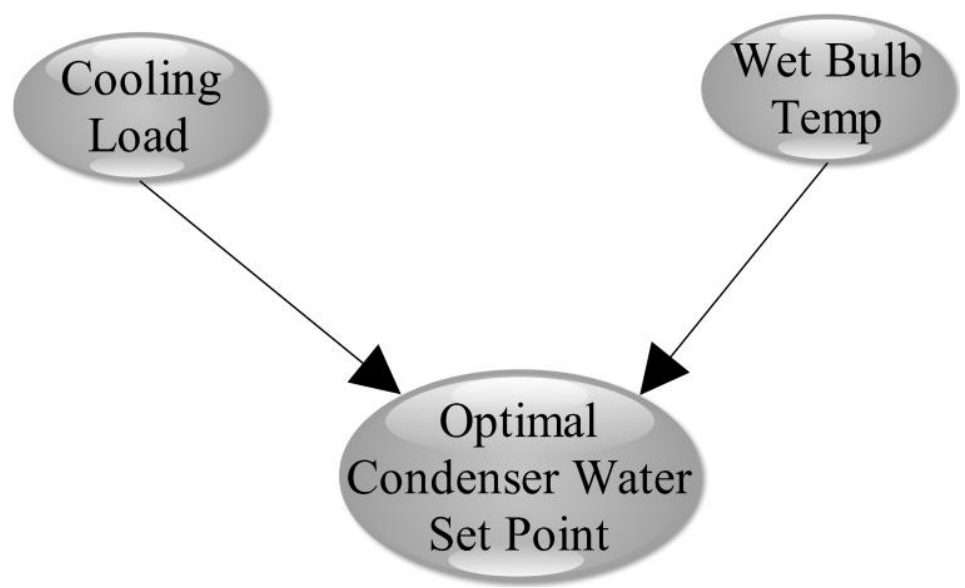

Figure 4. The structure of the Bayesian Network model for the optimization of the condenser water set point

\subsection{Regression Models for Comparison}

To evaluate the proposed Bayesian Network model, we compare its performance with that of two regressing models: one is a linear regression model defined by equation (1) (Sun and Reddy 2005), and the other one is a polynomial model defined as

$$
T_{c w, \text { set }, \text { opt }}=c_{1}+c_{2} T_{w b}+c_{3} \frac{\dot{Q}}{\dot{Q}_{\text {nom }}}+c_{4}\left(\frac{\dot{Q}}{\dot{Q}_{\text {nom }}}\right)^{2},
$$

where $c_{1}, c_{2}, c_{3}$, and $c_{4}$ are regression coefficients. Equation (8) is derived from the equation (2). In equation (2), the coefficient of the wet bulb temperature is 1 , which means when the wet bulb temperature changes by $1.0^{\circ} \mathrm{C}$, the optimal condenser water set point will always change by $1.0^{\circ} \mathrm{C}$. However, with different characteristics of chillers and cooling towers, it is possible that the relationship between the optimal condenser water set point and the wet bulb temperature changes by chiller plants. With that in mind, we treat the coefficient of the wet bulb temperature as one regression coefficient in equation (8). Similar to the proposed Bayesian Network model, the optimal condenser water set points predicted by the regression models are also limited in the range $[15.1,26.1]\left({ }^{\circ} \mathrm{C}\right)$. 
The regression coefficients in the linear and the polynomial models are estimated by the ordinary least squares method (Groß 2012). The ordinary least squares method estimates the unknown parameters in regression models by solving the following optimization problem:

$$
J=\min \left(\sum_{i=1}^{N_{o b}}\left(y_{i}-\hat{y}_{i}\right)^{2}\right)=\min \left(f_{3}\left(r_{1}, \ldots, r_{n}\right)\right),
$$

where $y_{i}$ is the $i$ th observed value of the dependent variable, $\hat{y}_{i}$ is the corresponding predicted value of the dependent variable by the recession model, $N_{o b}$ is the number of the observed values, and $r_{1}, \ldots, r_{n}$ are the regression coefficients.

\subsection{The Training Dataset}

To generate a training dataset for the proposed Bayesian Network model and the regression models, we use the following approach shown in Figure 5:

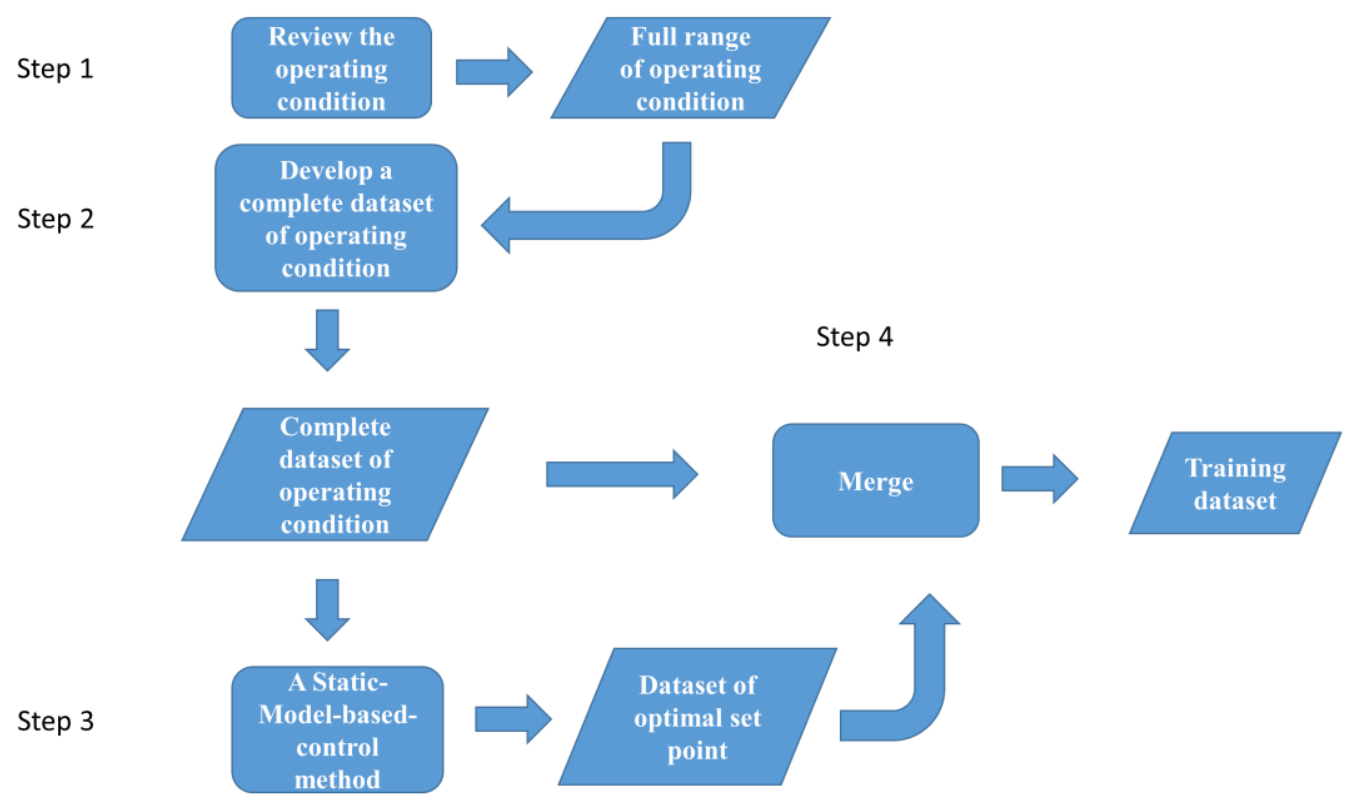

Figure 5. The procedure for generating a training dataset 
In Step 1, we review the studied chiller plant's typical operating condition. Over the course of a year, we find the cooling load ranged from 0 to around 2000 Ton while the wet bulb temperature changed from around $-11.0^{\circ} \mathrm{C}$ to $25.0^{\circ} \mathrm{C}$.

In Step 2, we develop a complete dataset for the cooling loads and the wet bulb temperatures based on their ranges obtained in Step 1. In the dataset, the cooling load range is $[50,2000]$ (Ton) with an interval of 50 Ton and the wet bulb temperature range is $[-11.0,25.0]$ $\left({ }^{\circ} \mathrm{C}\right)$ with an interval of $0.5^{\circ} \mathrm{C}$.

In Step 3, the complete set for the cooling load and the wet bulb temperature is used as the inputs for a model-based optimization scheme to find the corresponding optimal condenser water set points. For the model-based optimization scheme, the optimization problem is the same as that defined in equation (6). In this model-based optimization scheme, we model the studied chiller plant with Modelica (Modelica Association) so that the values of the objective function under different condenser water set points can be obtained by the system model. In the Modelica model, an ElectricEIR model in the Modelica Buildings library (Wetter et al. 2014) was used to model the chillers. The ElectricEIR model calculates the actual power of the chiller, $P_{c h}$, using:

$$
P_{c h}=P_{c h, n o m} \operatorname{CAPFT}\left(T_{c h w, l e a}, T_{c w, e n t}\right) \operatorname{EIRFT}\left(T_{c h w, l e a}, T_{c w, e n t}\right) \operatorname{EIRFPLR},
$$

where $P_{c h, n o m}$ is the nominal power of the chiller. CAPFT is a curve that represents the available capacity as a function of the temperature of chilled water leaving the chiller, $T_{c h w, l e a}$, and the temperature of the condenser water entering the chiller, $T_{c w, e n t}$. EIRFT is a curve that represents the full-load efficiency as a function of $T_{c h w, l e a}$ and $T_{c w, e n t}$. EIRFPLR is a curve that represents the efficiency as a function of the percentage unloading. In this study, the operation curves of 
Tran_CVHF_2799kW from manufactures were adapted. In addition, a YorkCalc model in the Buildings library was also employed to calculate the power of the cooling tower. The YorkCalc model calculates the approach temperature (the difference between the temperature of the condenser water leaving the cooling tower and the wet bulb temperate) using a purely-empirical YorkCalc correlation:

$$
\begin{gathered}
\Delta T_{a p p}=-0.359741205-0.055053608 T_{w b}+0.0023850432 T_{w b}{ }^{2}+0.173926877 \Delta T_{r}- \\
0.0248473764 T_{w b} \Delta T_{r}+0.00048430224 T_{w b}{ }^{2} \Delta T_{r}-0.005589849456 \Delta T_{r}{ }^{2}+ \\
0.0005770079712 T_{w b} \Delta T_{r}{ }^{2}-0.00001342427256 T_{w b}{ }^{2} \Delta T_{r}{ }^{2}+2.84765801111111 L G R- \\
0.121765149 T_{w b} L G R+0.0014599242 T_{w b}{ }^{2} L G R+1.680428651 T_{r} L G R- \\
0.0166920786 T_{w b} \Delta T_{r} L G R-0.0007190532 T_{w b}{ }^{2} \Delta T_{r} L G R-0.025485194448 \Delta T_{r}{ }^{2} L G R+ \\
0.0000487491696 T_{w b} \Delta T_{r}{ }^{2} L G R+0.00002719234152 T_{w b}{ }^{2} \Delta T_{r}{ }^{2} L G R- \\
0.0653766255555556 G R^{2}-0.002278167 T_{w b} L G R^{2}+0.0002500254 T_{w b}{ }^{2} L G R^{2}- \\
0.0910565458 \Delta T_{r} L G R^{2}+0.00318176316 T_{w b} \Delta T_{r} L G R^{2}+0.000038621772 T_{w b}{ }^{2} \Delta T_{r} L G R^{2}- \\
0.0034285382352 \Delta T_{r}{ }^{2} L G R^{2}+0.00000856589904 T_{w b} \Delta T_{r}{ }^{2} L G R^{2}- \\
0.000001516821552 T_{w b}{ }^{2} \Delta T_{r}{ }^{2} L G R^{2},
\end{gathered}
$$

where $\Delta T_{r}$ is the temperature of the condenser water entering cooling tower minus the temperature of the condenser water leaving cooling tower and $L G R$ is the ratio of the condenser water flow rate to the airflow rate. The fan power $P_{t w}$ is computed as

$$
P_{t w}=P_{t w, n o m} y^{3} \text {. }
$$

where $y$ is the fan speed ratio and $P_{t w, n o m}$ is the nominal fan power.

Moreover, Modelica_StateGraph2 library (Otter, Årzén, and Dressler 2005) is used to model the control system of the studied chiller plant. To guarantee that we can achieve the optimal solution, we use an exhaustive search method to evaluate all the possible condenser water set points. We limit the selection range in the range for the possible condenser water set points as $[15.1,26.1]\left({ }^{\circ} \mathrm{C}\right)$. The interval for this range is set to be $0.1^{\circ} \mathrm{C}$ since the accuracy level of water temperature sensor is normally $0.1^{\circ} \mathrm{C}$ in real practice. A more detailed description of the model-based optimization configuration can be referred in the literature (Huang and Zuo 2014). 
In Step 4, the generated optimal condenser water set points are merged with the complete dataset for the cooling load and the wet bulb temperature data to develop a complete training dataset.

\subsection{Testing}

To evaluate the performances of the proposed Bayesian Network model and the regression models, we use them to predict the optimal condenser water set points for two testing months: one mild month (April 2012) and one summer month (July 2012) in Washington. D.C. The two months represent the mild season and the summer season, respectively. The historic hourly data of the cooling load from an on-site measurement of three office buildings and the wet bulb temperature from a nearby weather station (National Climatic Data Center) are used. The data is shown in Figure 6 and Figure 7.
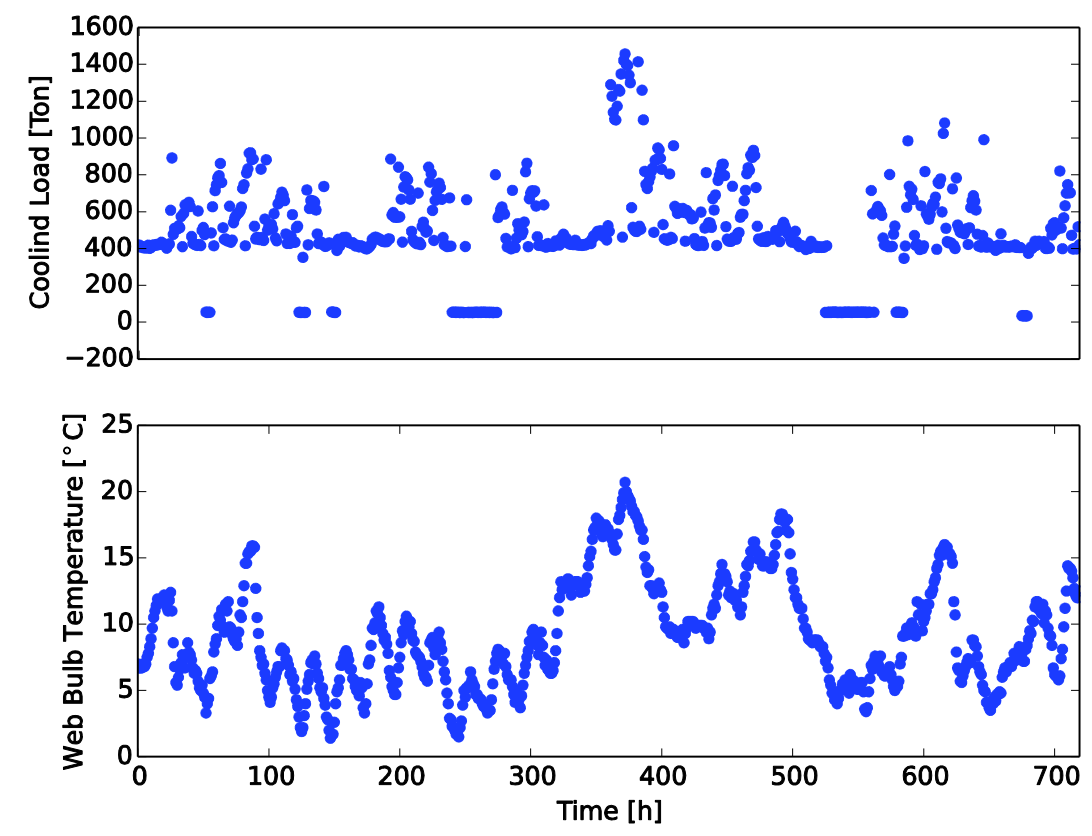

Figure 6 . The hourly cooling load and wet bulb temperature data for the mild month in Washington D.C. 

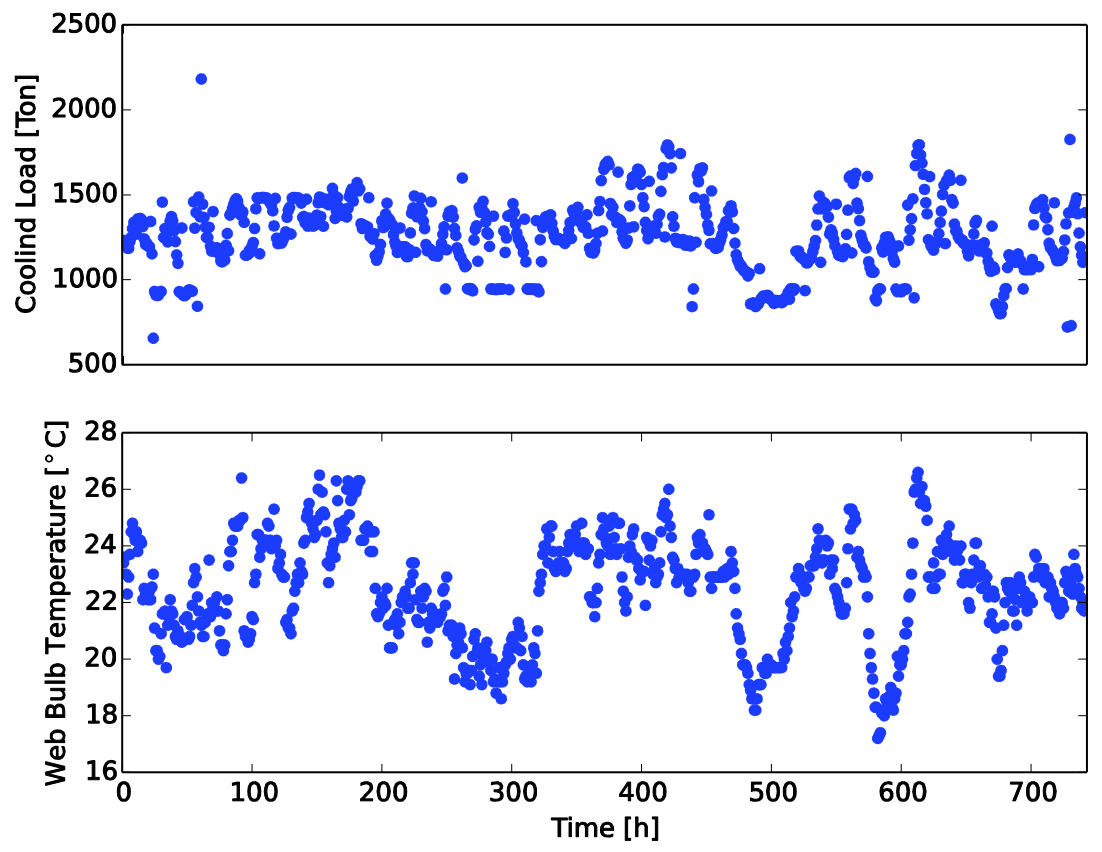

Figure 7. The hourly cooling load and wet bulb temperature data for the summer month in Washington D.C.

To evaluate the performance of the Bayesian Network model, we also used the modelbased optimization scheme (section 3.4) to predict the optimal condenser water set points for the testing periods. The model-based optimization method finds the most optimal results by conducting the exhaustive search method.

To investigate how the condenser water set point prediction affects the energy performance of the studied chiller plant, we calculate the total power used by the chillers and the cooling towers according to the predicted condenser water set point via simulation. The system model is the same as that in the model-based optimization method (section 3.4). We then calculate the energy consumption by the chillers and the cooling towers during the testing period by the following equation:

$$
E=\sum_{i}^{m} 3600 P_{\text {sum }}(i)
$$


where $P_{\text {sum }}(i)$ is the total power used by the chillers and the cooling towers at the $i$ th hour while $m$ is the number of hour in the testing period.

\subsection{Results}

\subsubsection{The Impact of the Discretization Intervals on the Accuracy of the Bayesian Network} model

In the proposed Bayesian Network model, the parent nodes are the cooling load and the wet bulb temperature, which are continuous variables. As mentioned in section 2.2 , we have to discretize the continuous variables in the Bayesian Network model. To identify the appropriate intervals for the discretization, we perform the following sensitivity study using the training dataset generated at intervals of $0.5^{\circ} \mathrm{C}$ for the wet bulb temperature and 50 ton for the cooling load:

- Firstly, we fixed the interval for the cooling load as 100 Ton and changed the interval for the wet bulb temperature into $0.75,1,2,4$, and $8^{\circ} \mathrm{C}$, respectively.

- Then, we fixed the interval for the wet bulb temperature as $1^{\circ} \mathrm{C}$ and changed the interval for the cooling load into 75, 100, 200, 400, and 800 Ton, respectively.

Figure 8 shows the results of the sensitivity study. We can see that the Root Mean Square Deviation (RMSD) of the prediction of the entire testing period by the Bayesian Network model to the results by the Model-based Optimization method changes from 1.33 to $0.2^{\circ} \mathrm{C}$ when the interval for the wet bulb temperature decreases from 8 to $0.75^{\circ} \mathrm{C}$. In average, the RMSD decreases by $0.15^{\circ} \mathrm{C}$ by $1^{\circ} \mathrm{C}$ reduction in the interval for the wet bulb temperature. It is possible to further reduce the interval to achieve a lower RMSD till $0.2^{\circ} \mathrm{C}$. However, reducing the interval would require a significant amount of computing time to generate the training data in a finer 
interval. Similarly, the RMSD decreases in average by around $0.01^{\circ} \mathrm{C}$ by 100 Ton reduction in the interval for the cooling load.
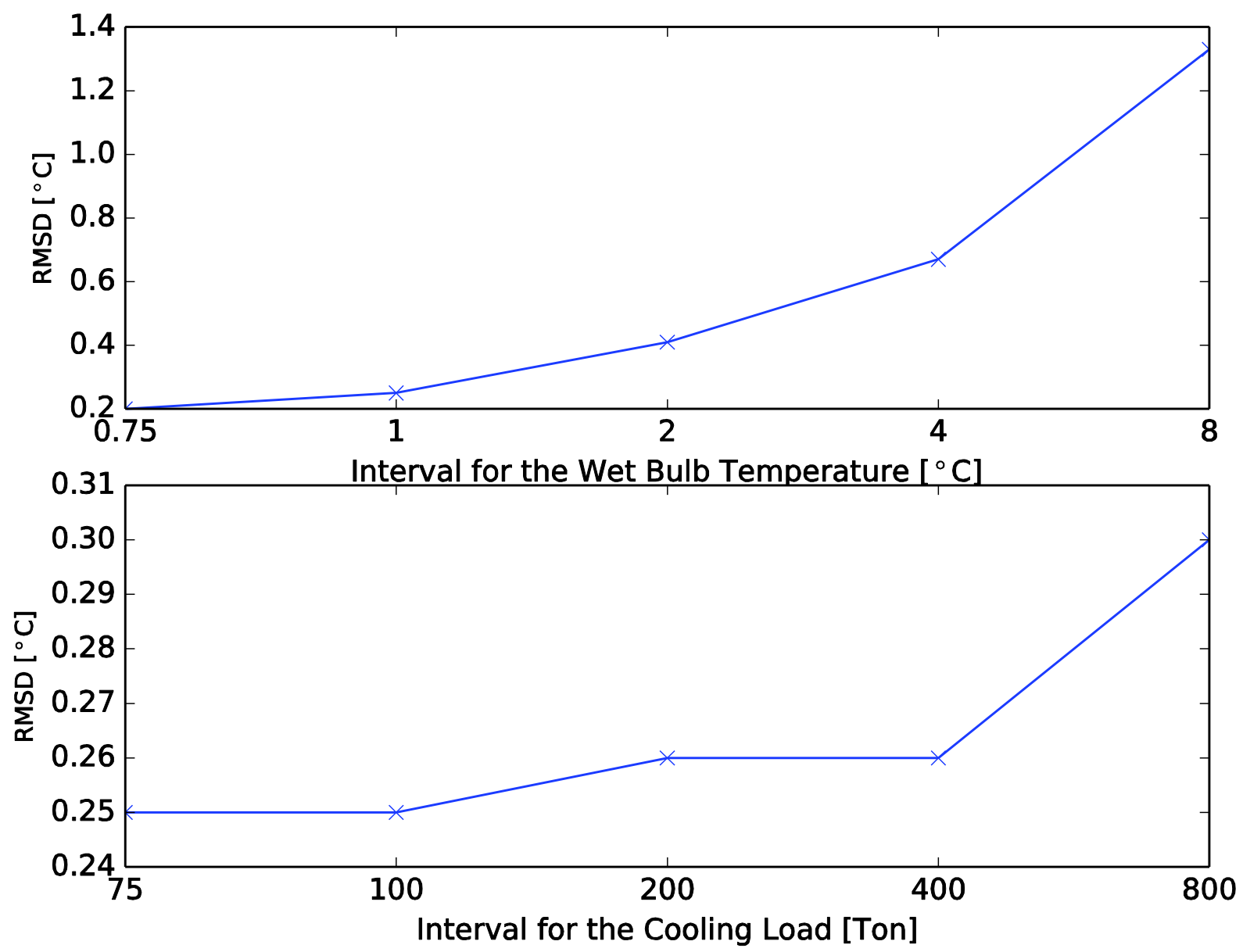

Figure 8 . The results for the sensitivity study regarding the discretization intervals for the Bayesian Network model: (top) the interval for the cooling load is fixed as 100 Ton; (b) the interval for the wet bulb temperature is fixed as $1^{\circ} \mathrm{C}$

\subsubsection{Detailed Result for the Prediction}

In this section, we demonstrate the results for the Bayesian Network model when the interval of the cooling load and the wet bulb temperature as 100 Ton and $1^{\circ} \mathrm{C}$, respectively. The general simulation results are shown as Table 1 (the generated look-up table can be found in Appendix). 
In the mild month (April 2012), the Bayesian Network model predicts the optimal condenser water set point with a RMSD of $0.20^{\circ} \mathrm{C}$. As a result, the energy saving ratio for the Bayesian Network model $(25.92 \%)$ is close to the theoretically upper limit $(26.04 \%)$. On the contrary, both the linear and the polynomial models have a relatively large error with a RMSD of $2.3^{\circ} \mathrm{C}$. The large errors in condenser water set point predictions by the linear and the polynomial models lead to less energy savings (up to $12,500 \mathrm{kWh}$ ) than the Bayesian Network model.

Table 1 The general results for the testing set

\begin{tabular}{|c|c|c|c|c|c|}
\hline & & $\begin{array}{l}\text { Bayesian } \\
\text { Network } \\
\text { Model }\end{array}$ & $\begin{array}{c}\text { Linear Regression } \\
\text { Model }\end{array}$ & $\begin{array}{c}\text { Polynomial } \\
\text { Regression Model }\end{array}$ & $\begin{array}{c}\text { Model-based } \\
\text { Optimization } \\
\text { Method } \\
\end{array}$ \\
\hline \multirow{3}{*}{$\begin{array}{c}\text { Mild } \\
\text { Month }\end{array}$} & $\begin{array}{l}\text { RMSD from the } \\
\text { Optimal Condenser } \\
\text { Water Set Point } \\
\text { Prediction }\left[{ }^{\circ} \mathrm{C}\right]\end{array}$ & 0.2 & 2.3 & 2.3 & N/A \\
\hline & $\begin{array}{c}\text { Energy Consumption } \\
\text { by the Chillers and } \\
\text { the Cooling Towers } \\
{[\mathrm{kWh}]}\end{array}$ & 133,477 & 145,954 & 146,022 & 133,271 \\
\hline & $\begin{array}{l}\text { Energy Saving Ratio } \\
\text { for the Chillers and } \\
\text { the Cooling Towers }\end{array}$ & $25.92 \%$ & $19.00 \%$ & $18.96 \%$ & $26.04 \%$ \\
\hline \multirow{3}{*}{$\begin{array}{l}\text { Summer } \\
\text { Month }\end{array}$} & $\begin{array}{l}\text { RMSD from the } \\
\text { Optimal Condenser } \\
\text { Water Set Point } \\
\text { Prediction }\left[{ }^{\circ} \mathrm{C}\right] \\
\end{array}$ & 0.3 & 3.3 & 3.3 & N/A \\
\hline & $\begin{array}{c}\text { Energy Consumption } \\
\text { by the Chillers and } \\
\text { the Cooling Towers } \\
{[\mathrm{kWh}]}\end{array}$ & 486,117 & 511,345 & 511,139 & 485,262 \\
\hline & $\begin{array}{l}\text { Energy Saving Ratio } \\
\text { for the Chillers and } \\
\text { the Cooling Towers }\end{array}$ & $1.39 \%$ & $-3.73 \%$ & $-3.69 \%$ & $1.56 \%$ \\
\hline
\end{tabular}

(In the baseline for both the mild month and the summer month, the condenser water set point is fixed as $\left.26.1^{\circ} \mathrm{C}\right)$

In the summer month (July 2012), the accuracy of the Bayesian Network model in predicting the optimal condenser water set points is also close to the real optimum with a RMSD of $0.3^{\circ} \mathrm{C}$. Thus, the decrease in the energy saving ratio by the Bayesian Network model compared 
to the theoretically upper limit is only $0.17 \%$. On the other hand, the linear and the polynomial models have relatively poor predictions with a RMSD of $3.3^{\circ} \mathrm{C}$. The poor predictions of the linear and polynomial models result in even more energy than the baseline with increases by $3.73 \%$ and $3.69 \%$, respectively. In other words, plants using these two models will consume up to $25,200 \mathrm{kWh}$ more energy compared to the one using the Bayesian Network model.

The above analysis shows that the performance of the Bayesian Network model is much better than that of the linear and the polynomial models in predicting the optimal condenser water set points for both the mild month and the summer month. Moreover, larger prediction errors of the linear and the polynomial models tend to increase the energy consumption.

\subsubsection{Typical Days}

In order to understand how the optimal condenser water set point predictions affect the plant operation, we select two typical days from the two months: a mild day (April 20th, Friday) and a summer day (July 20th, Friday). In the mild day, the cooling load changed from around 400 Ton to 900 Ton and the wet bulb temperature was from $11.0^{\circ} \mathrm{C}$ to $16.0^{\circ} \mathrm{C}$ (Figure 9). The condenser water set points predicted by the Bayesian Network model are quite close to the optimal solution (predicted by the model-based optimization scheme): the highest deviation is $0.7^{\circ} \mathrm{C}$. The linear and the polynomial models have similar condenser water set point predictions and the condenser water set points predicted by those two methods are always larger than that the optimal solution. As a result of different condenser water set point predictions, the Bayesian Network model, the linear model, and the polynomial model achieve $20.41 \%, 15.66 \%$ and $15.63 \%$ daily energy savings for the chillers and cooling towers, respectively. As a reference, the model-based optimization method achieves a $20.66 \%$ daily energy saving. 

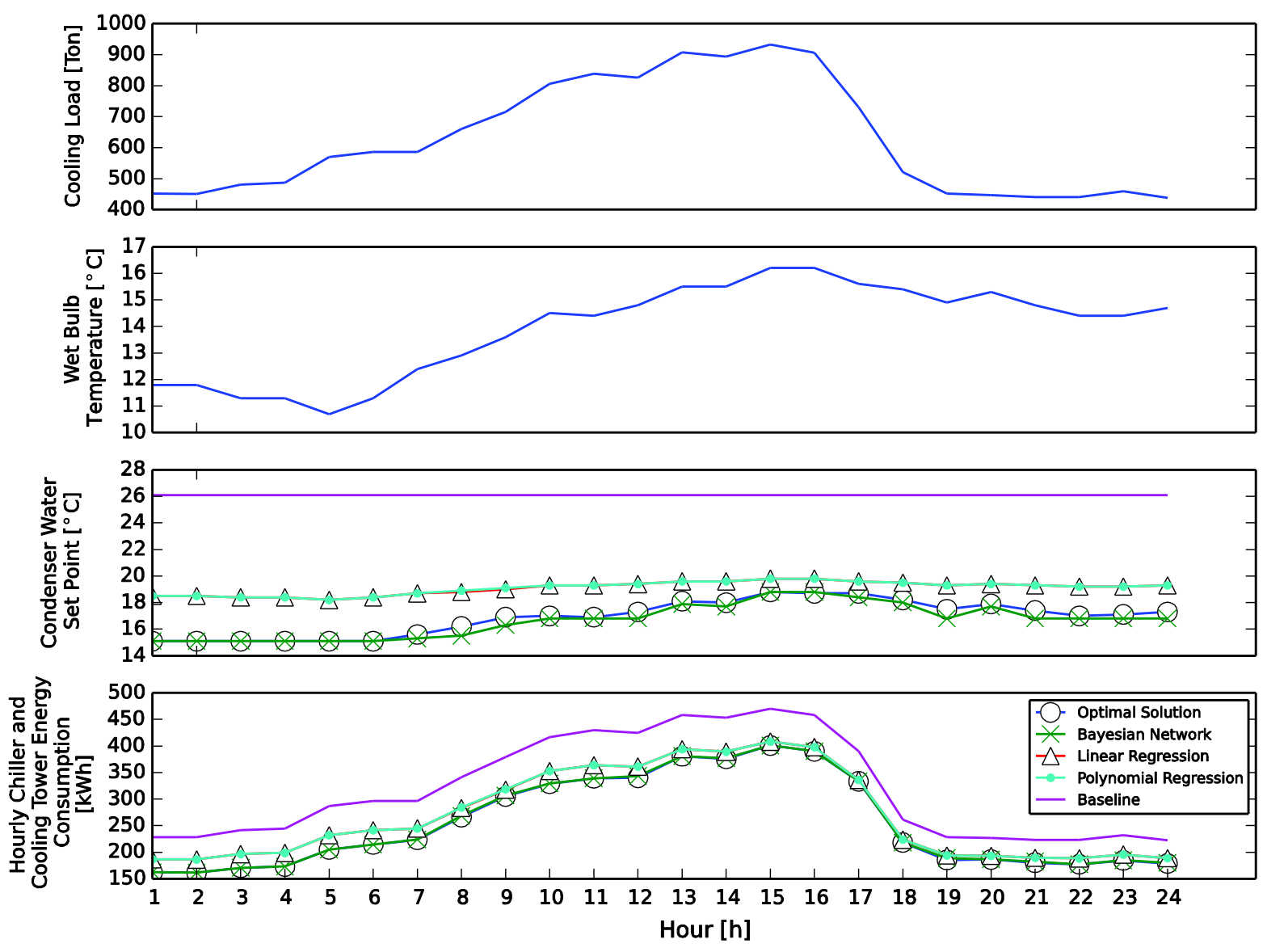

Figure 9. The cooling load, wet bulb temperature, predicted condenser water set point, and the total chiller and cooling tower energy consumption of the mild day

As shown in Figure 10, the cooling load and wet bulb temperature in the summer day are higher than those in the mild day in Figure 9. Since the condenser water set point should be always higher than the wet bulb temperature, there is smaller room for optimizing the condenser water set points with higher wet bulb temperature. Thus, the optimal solution only achieves a $1.25 \%$ daily energy saving for the chillers and the cooling towers in the summer day. The Bayesian Network model achieves a condenser water set point prediction relatively closer to the optimal solution. The condenser water set points predicted by the linear and polynomial models 
are much lower than that by the optimal solution and sometimes are even less than the wet bulb temperature, which is not possible. In consequence, the Bayesian Network method achieves a $0.87 \%$ daily energy saving while both the linear and polynomial models increase the daily energy consumption for the chillers and the cooling towers by $5.08 \%$.
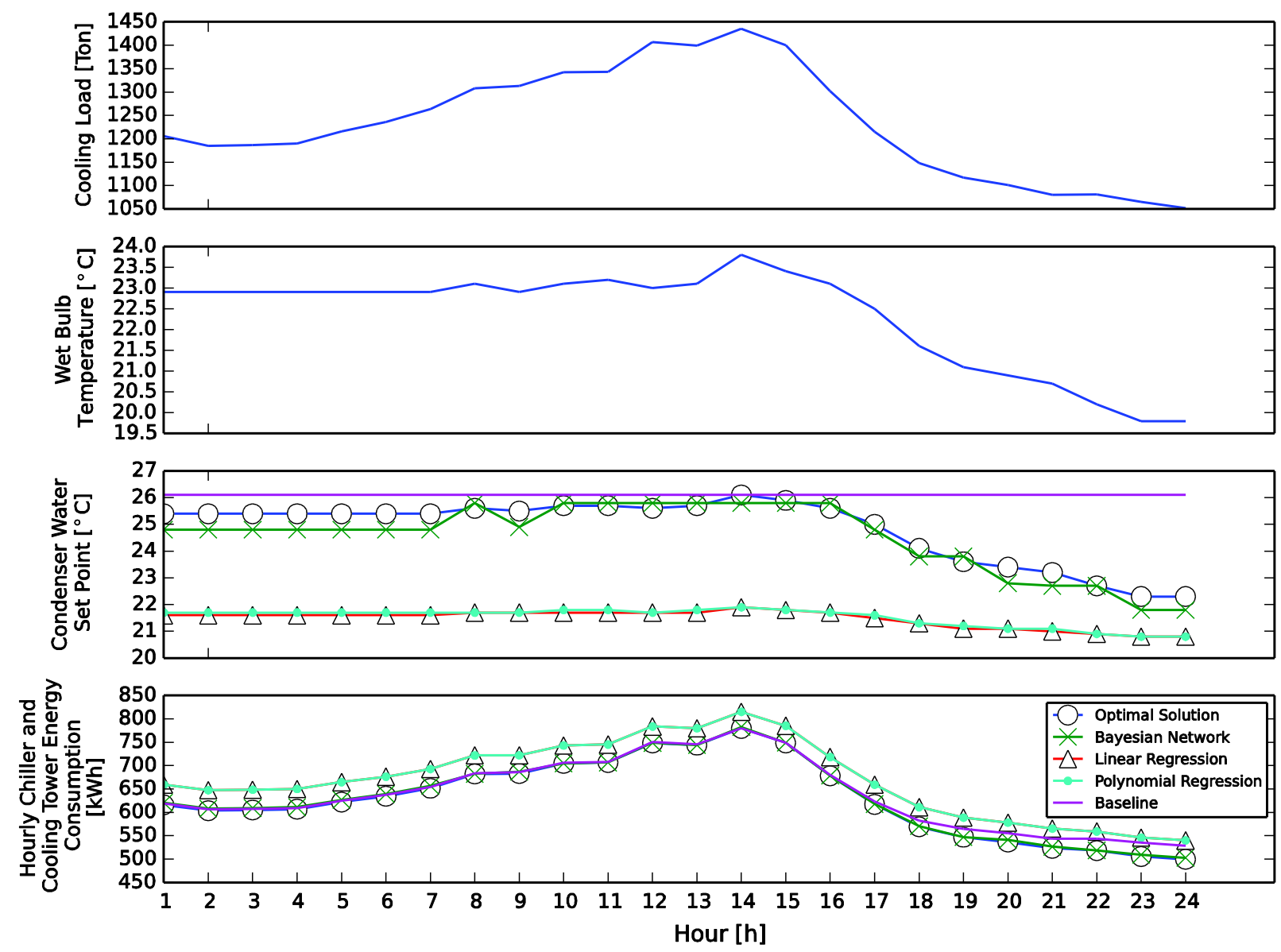

Figure 10. The cooling load, wet bulb temperature, predicted condenser water set point, and the total chiller and cooling tower energy consumption of the summer day

As shown in Figure 9 and Figure 10, the linear and polynomial models overestimate the optimal condenser water set point in the mild season and underestimate it in the summer season. This is because those models can't track the nonlinear trend of the optimal condenser water set point which is changing by the operating conditions. To achieve the minimum summation of the 
prediction deviation (see equation (9)), they tend to predict the condenser water set point, which is close to the mean value of the set points in the training dataset. As a result, it will lead to underestimations when the optimal condenser water set point is higher in the summer season and overestimations when the optimal condenser water set point is lower in the mild season.

\section{Conclusion}

In this paper, we developed a Bayesian Network model for predicting the optimal condenser water set points. We compared the performance of the Bayesian Network model with those of a linear model and a polynomial model via a case study. Based on the result of the case study, we can draw the following conclusions:

- The Bayesian Network model is able to represent the relationship between the cooling load, the wet bulb temperature, and the corresponding optimal condenser water set points with a good accuracy. It may be a promising approach for fast selection of the optimal condense water set point;

- The Bayesian Network model can significantly increase the energy saving by the condenser water set point optimization compared to the linear and the polynomial models.

It is our view that to realize the energy savings in real building systems, a simple and effective mechanism to obtain the optimal control settings is indispensable. Compared to the model-based optimization methods, the proposed Bayesian Network model significantly reduces the requirement for real-time computational resources, which is essential especially for legacy building systems. In addition, the computation for generating the training dataset can be performed before the implementation, which usually doesn't cause challenges without limits of computational resources. At the same time, the Bayesian Network model achieves a much better 
accuracy in predicting the optimal condenser water set point than the commonly used linear and the polynomial models. Because of those, we believe the Bayesian Network model is promising for large-scale applications.

It should be noted that, however, the condenser water set point optimization was assumed to be steady state in this paper. For chiller plants with thermal storage devices or lager distribution loops, we may need to consider the dynamics of the chiller plants by introducing the time and the state vector as parent nodes in the Bayesian Network model, which should be considered in the future study.

This research has lay out the framework of applying the Bayesian Network models for the condenser water set point optimization although we only demonstrated the performance using a single chiller plant with one type of climate condition. Future research can extend the evaluation to a larger scope including different cooling load profiles, different equipment characteristics and different weather conditions, based on which a comprehensive conclusion can be draw. In addition, it will be also interesting to investigate if it is possible to apply the proposed Bayesian Network model in the optimization on the operation of the entire chiller plant in the future study.

Moreover, to enable a successful implementation of the proposed Bayesian Network model, an accurate system model is essential. In fact, there are many existing calibration technologies can be used to calibrate the chiller plant model, such as the one reported by Hydeman and Gillespie (2002). In the future study, we will study on developing an automatic 
mechanism to streamline the calibration process so that efforts for implementation can be reduced.

Lastly, in the future study, we will also study if the accuracy of the Bayesian Network model can be further increased by employing a continuous Bayesian Network model and letting the Bayesian Network model learn the structure from training dataset rather than using a predefined structure as we did in this study. In addition, to simplify the evaluation of the Bayesian Network model, we assumed the model that we used to generate the training dataset was prefect, which means there is no uncertainty in the training dataset. However, the uncertainties are inevitable in the real world. Therefore, it will be beneficial to study how the prediction of the Bayesian Network model is affected by the uncertainties in the future. Moreover, the future research should also include an intensive study on the sensitivity of the Bayesian Network model to the discretization settings, based on which we could balance the accuracy with the efforts to generate the training dataset.

\section{Acknowledgement}

This research was supported by the U.S. Department of Defense under the ESTCP program. The authors thank Marco Bonvini, Michael Wetter, Mary Ann Piette, Jessica Granderson, Oren Schetrit, Rong Lily Hu and Guanjing Lin for the support provided through the research. The second author performed this research as a visiting student at the University of Miami with the support of Brazilian Scientific Mobility Program. 
This research also emerged from the Annex 60 project, an international project conducted under the umbrella of the International Energy Agency (IEA) within the Energy in Buildings and Communities (EBC) Programme. Annex 60 will develop and demonstrate new-generation computational tools for building and community energy systems based on Modelica, Functional Mockup Interface and BIM standards.

\section{Appendix}

Part of the Generated Look-up Table

\begin{tabular}{|c|c|c|}
\hline $\begin{array}{c}\text { Cooling } \\
\text { Load } \\
\text { Range } \\
{[\text { Ton] }}\end{array}$ & $\begin{array}{c}\text { Wet Bulb } \\
\text { Temperature } \\
{\left[{ }^{\circ} \mathbf{C}\right]}\end{array}$ & $\begin{array}{c}\text { The Optimal Condenser Water } \\
\text { Temperature Set Point } \\
{\left[{ }^{\circ} \mathbf{C}\right]}\end{array}$ \\
\hline$\ldots$ & $\ldots$ & $\ldots$ \\
\hline$[600,700)$ & {$[12.0,13.0)$} & 15.5 \\
\hline$[600,700)$ & {$[13.0,14.0)$} & 16.4 \\
\hline$[600,700)$ & {$[14.0,15.0)$} & 17.4 \\
\hline$[600,700)$ & {$[15.0,16.0)$} & 18.3 \\
\hline$[600,700)$ & {$[16.0,17.0)$} & 19.2 \\
\hline$[600,700)$ & {$[17.0,18.0)$} & 20.1 \\
\hline$[600,700)$ & {$[18.0,19.0)$} & 21.1 \\
\hline$[600,700)$ & {$[19.0,20.0)$} & 22.0 \\
\hline$[600,700)$ & {$[20.0,21.0)$} & 22.9 \\
\hline$[600,700)$ & {$[21.0,22.0)$} & 23.9 \\
\hline$[600,700)$ & {$[22.0,23.0)$} & 24.8 \\
\hline$[600,700)$ & {$[23.0,24.0)$} & 25.8 \\
\hline$[600,700)$ & {$[24.0,25.0)$} & 26.1 \\
\hline$\ldots$ & $\ldots$ & $\ldots$ \\
\hline
\end{tabular}

\section{Reference}

A. R. Al-Ali, M. M. Negm, and M. Kassas. 2000. A PLC Based Power Factor Controller for a 3-Phase Induction Motor Paper presented at the Industry Applications Conference. ASHRAE. 2011. ASHRAE Handbook HVAC Application. Atlanta: ASHRAE, Inc.

J. E. Braun, and G. T. Diderrich. 1990. "Near-optimal Control of Cooling Towers for Chilled-water Systems."ASHRAE Transactions 96 (2):806-16. 
C. C. Chang, S. S. Shieh, S. S. Jang, C. W. Wu, and Y. Tsou. 2015. "Energy Conservation Improvement and ON-OFF Switch Times Reduction for An Existing VFD-fan-based Cooling Tower."Applied Energy 154 (2015):491-9.

Y. C. Chang. 2004. "A Novel Energy Conservation Method - Optimal Chiller Loading."Electric Power Systems Research 69 (2-3):221-6. doi: DOI 10.1016/j.epsr.2003.10.012.

K. J. Chua, S. K. Chou, W. M. Yang, and J. Yan. 2013. "Achieving Better Energy-efficient Air Conditioning - a Review of Technologies and Strategies."Applied Energy 104 (2013):87-104.

B. R. Cobb, R. Rum, and A. Salmerón. 2007. "Bayesian Network Models with Discrete and Continuous Variables." In Advances in Probabilistic Graphical Models, edited by Peter Lucas, José A. Gámez and Antonio Salmerón D. Berlin: Springer Berlin Heidelberg.

B. Coffey. 2011. "Using Building Simulation and Optimization to Calculate Lookup Tables for Control." University of California, Berkeley.

N. Friedman, and M. Goldszmidt. 1996. Discretizing Continuous Attributes While Learning Bayesian Networks. Paper presented at the International Conference on Machine Learning, Bari, Italy.

J. Groß. 2012. Linear Regression. Berlin: Springer Science \& Business Media.

J. C. Helton, and F. J. Davis. 2003. "Latin Hypercube Sampling and the Propagation of Uncertainty in Analyses of Complex Systems." Reliability Engineering \& System Safety 81 (2003):23-69.

S. Huang, and W. Zuo. 2014. Optimization of the Water-cooled Chiller Plant System Operation. Paper presented at the ASHRAE/IBPSA-USA Building Simulation Conference, Atlanta, GA, U.S.A.

S. Huang, W. Zuo, and M. D. Sohn. 2015. A New Method for the Optimal Chiller Sequencing Control. Paper presented at the the 14th Conference of IBPSA, Hyderabad, India.

S. Huang, W. Zuo, and M. D. Sohn. 2016a. "Amelioration of the Cooling Load based Chiller Sequencing Control."Applied Energy 168 (2016):204-15.

S. Huang, W. Zuo, and M. D. Sohn. 2016b. "Improved Cooling Tower Control of Legacy Chiller Plants by Optimizing the Condenser Water Set Point."Building and Environment In Press.

M. Hydeman, and K. L. Gillespie. 2002. "Tools and Techniques to Calibrate Electric Chiller Component Models."ASHRAE Transactions 108 (2002):733-41.

S. Imoto, T. Higuchi, S. Y. Kim, E. Jeong, and S. Miyano. 2005. "Residual Bootstrapping and Median Filtering for Robust Estimation of Gene Networks from Microarray Data." In Computational Methods in Systems Biology: International Conference CMSB 2004, Paris, France, May 26-28, 2004, Revised Selected Papers, edited by Vincent Danos and Vincent Schachter, 149-60. Springer Science \& Business Media.

K. L. Jensen, J. Toftum, and P. Friis-Hansen. 2009. "A Bayesian Network Approach to the Evaluation of Building Design and its Consequences for Employee Performance and Operational Costs." Building and Environment 44 (2009):456- 62.

J. Kim, Y.-G. Kim, and J. An. 2011. "A Fuzzy Obstacle Avoidance Controller using a Lookup-Table Sharing Method and Its Applications for Mobile Robots." International Journal of Advanced Robotic Systems 8 (5):39-48.

K. P. Lee, and T. A. Cheng. 2012. "A Simulation-optimization Approach for Energy Efficiency of Chilled Water System."Energy and Buildings 54 (2012):290-6.

W. S. Lee, and L. C. Lin. 2009. "Optimal Chiller Loading by Particle Swarm Algorithm for Reducing Energy Consumption."Applied Thermal Engineering 29 (8-9):1730-4.

Z. Li, G. Huang, and Y. Sun. 2014. "Stochastic Chiller Sequencing Control."Energy and Buildings 84 (2014):203-13.

L. Lu, W. Cai, Y. C. Soh, L. Xie, and S. Li. 2004. "HVAC System Optimization - Condenser Water Loop."Energy Conversion and Management 45 (4):613-30.

Z. Ma, S. Wang, X. Xu, and F. Xia. 2008. "A Supervisory Control Strategy for Building Cooling Water Systems for Practical and Real Time Applications."Energy Conversion and Management 49 (8):2324-36. doi: DOI 10.1016/j.enconman.2008.01.019. 
Z. Ma, S. Wang, X. Xu, and F. Xia. 2009. "An Optimal Control Strategy for Complex Building Central Chilled Water Systems for Practical and Real-time Applications." Building and Environment 44 (6):1188-98. doi: DOI 10.1016/j.buildenv.2008.08.011.

A. C. L. Malara, S. Huang, W. Zuo, M. D. Sohn, and N. Celik. 2015. Optimal Control of Chiller Plants using Bayesian Network. Paper presented at the The 14th International Conference of the IBPSA Hyderabad.

Modelica Association. 2015. Accessed May 22. https://www.modelica.org/.

National Climatic Data Center. 2015. "Quality Controlled Local Climatological Data." Accessed May 14. http://www.ncdc.noaa.gov/data-access/land-based-station-data/land-based-datasets/qualitycontrolled-local-climatological-data-qclcd.

Z. O'Neill. 2014. "Development of a Probabilistic Graphical Energy Performance Model for an Office Building."ASHRAE Transactions 120 (2).

M. Otter, K.-E. Årzén, and I. Dressler. 2005. StateGraph - a Modelica Library for Hierarchical State Machines. Paper presented at the the 4th International Modelica Conference, Hamburg, Germany.

J. Sun, and A. Reddy. 2005. "Optimal Control of Building HVAC\&R Systems using Complete Simulation-based Sequential Quadratic Programming (CSB-SQP)."Building and Environment 40 (5):657-69.

Y. Sun, S. Wang, and F. Xiao. 2013. "In Situ Performance Comparison and Evaluation of Three Chiller Sequencing Control Strategies in a Super High-rise Building." Energy and Buildings 61 (2013):333-43. doi: DOI 10.1016/j.enbuild.2013.02.043.

J. Toftum, R. V. Andersen, and K. L. Jensen. 2009. "Occupant Performance and Building Energy Consumption with Different Philosophies of Determining Acceptable Thermal Conditions."Building and Environment 44 (2009):2009-16.

Y. Wang, and S. Boyd. 2010. "Fast Model Predictive Control Using Online Optimization."IEEE Transactions on Control System Technology 18 (2):267-78.

D. Westphalen, and S. Koszalinski. 2001. "Energy Consumption Characteristics of Commercial Building HVAC Systems Volume I : Chillers, Refrigerant Compressors, and Heating Systems." In.: Arthur D. Little, Inc.

M. Wetter, W. Zuo, T. Nouidui, and X. Pang. 2014. "Modelica Buildings library."Journal of Building Performance Simulation 7 (4):253-70.

F. W. Yu, and K. T. Chan. 2007. "Optimum Load Sharing Strategy for Multiple-chiller Systems Serving Air-conditioned Buildings."Building and Environment 42 (4):1581-93.

F. W. Yu, and K. T. Chan. 2008. "Optimization of Water-cooled Chiller System with Load-based Speed Control."Applied Energy 85 (2008):931-50.

Z. Zhang, H. Li, W. D. Turner, and S. Deng. 2011. "Optimization of the Cooling Tower Condenser Water Leaving Temperature using a Component-based Model."ASHRAE Transactions 117 (1):934-44. 